\title{
Decorin is one of the proteoglycans expressed in Walker 256 rat mammary carcinoma
}

\section{S.M. Oba-Shinjo, \\ A.G.A. Berto, C.C. Passerotti, \\ C.D. Barbosa and \\ L.O. Sampaio}

Departamento de Bioquímica, Escola Paulista de Medicina, Universidade Federal de São Paulo, São Paulo, SP, Brasil

\author{
Correspondence \\ S.M. Oba-Shinjo \\ Av. Dr. Arnaldo, 455 \\ 4ㅇ andar, Sala 4110 \\ 01246-903 São Paulo, SP \\ Brasil \\ Fax: +55-11-3061-4036 \\ E-mail: suelimoba@lim15.fm.usp.br \\ Presented at SIMEC 2002 \\ (International Symposium \\ on Extracellular Matrix), \\ Angra dos Reis, RJ, Brazil, \\ October 7-10, 2002. \\ Research supported by FAPESP \\ and CNPq.
}

Received December 2, 2002

Accepted March 11, 2003

\begin{abstract}
Proteoglycan and glycosaminoglycan content was analyzed in a model of rat mammary carcinoma to study the roles of these compounds in tumorigenesis. Hyaluronic acid and proteoglycans bearing chondroitin and/or dermatan sulfate chains were detected in solid tumors obtained after subcutaneous inoculation of Walker 256 rat carcinoma cells. About $10 \%$ of sulfated glycosaminoglycan chains corresponded to heparan sulfate. The small leucine-rich proteoglycan, decorin, was identified as one of the proteoglycans, in addition to others of higher molecular weight, by cross-reaction with an antiserum raised against pig laryngeal decorin and by N-terminal amino acid sequencing. Decorin was separated from other proteoglycans by hydrophobic chromatography and its complete structure was determined. It has a molecular weight of about $85 \mathrm{kDa}$ and a dermatan chain of $45 \mathrm{kDa}$ with 4-sulfated disaccharides. After degradation of the glycosaminoglycan chain, three core proteins of different molecular weight (36, 46 and $56 \mathrm{kDa}$ ) were identified. The presence of hyaluronic acid and decorin has been reported in a variety of tumors and tumor cells. In the Walker 256 mammary carcinoma model, hyaluronic acid may play an important role in tumor progression, since it provides a more hydrated extracellular matrix. On the other hand, decorin, which is expressed by stromal cells, represents a host defense response to tumor growth.
\end{abstract}

Key words - Proteoglycan

- Glycosaminoglycan

- Walker 256 tumor

- Carcinoma

\section{Introduction}

Proteoglycans are complex macromolecules composed of a protein core to which at least one glycosaminoglycan chain is covalently linked. They are ubiquitous molecules and may be localized inside the cells, on the cell surface, or within the extracellular matrix. Proteoglycans also have a variety of functions in physiological and pathological conditions.
During tumor development, many alterations may occur in the composition of proteoglycans in the tissue. The main alteration is an increase in chondroitin sulfate (CS) content (1). Many different proteoglycans bearing CS chains have been described, such as the basal membrane proteoglycan perlecan (2), the high molecular weight proteoglycan versican/PG-M $(3,4)$ and the small extracellular proteoglycan decorin (5), amongst others. 
Decorin is a key regulator of extracellular matrix assembly and is a member of the small leucine-rich proteoglycan family (6). There is an increasing amount of evidence suggesting an important role of decorin in cell proliferation. Overexpression of decorin leads to growth inhibition in a variety of cell types $(7,8)$. Decorin may also play an important role in tumorigenesis, since not only does decorin expression decrease in various tumor cell types (9), but secretion of decorin by peritumoral stroma of colon cancer is also increased (10). This may represent a defense mechanism of the tumor stroma designed to counterbalance the invasive tumor cells.

Walker 256 is a rat cell lineage of mammary carcinoma discovered and isolated by George Walker in 1928 (11). Fiszer-Szafars and Giullino (12) observed the presence of hyaluronic acid (HA) in the interstitial fluid of this tumor. This in vivo animal model of neoplastic development, the Walker 256 mammary carcinoma, was used in the present study to analyze the compositions of glycosaminoglycan and proteoglycan. We confirmed that HA is present in this tumor and demonstrated that the small proteoglycan decorin is one of the proteoglycan expressed. Both HA and decorin are probably synthesized by stromal cells trying to defend the host against tumor cell growth.

\section{Material and Methods}

\section{Materials}

Guanidine hydrochlorate (GuaHCl), benzamidine $\mathrm{HCl}, \alpha$-aminocaproic acid, iodoacetamide, phenylmethylsulfonyl fluoride, HA (bovine trachea), chondroitinase ABC (Proteus vulgaris), deoxyribonuclease (DNase) I, and DEAE-cellulose were from Sigma (St. Louis, MO, USA). Anti-rabbit IgG, biotinylated whole goat streptavidin horseradish-peroxidase, Sepharose CL-4B and Octyl-Sepharose CL-4B were purchased from Amersham Biosciences (Uppsala, Sweden). Chondroitinase AC II (Arthrobacter aurenses) and standard glycosaminoglycans (chondroitin 4-sulfate, chondroitin 6-sulfate and dermatan sulfate, DS) were from Seikagaku Kogyo Co. (Tokyo, Japan). Heparan sulfate (HS) was prepared as described previously (13). The polyclonal antibody used was raised against pig laryngeal cartilage decorin (14). Tumoral cells of the Walker 256 strain or rat mammary carcinoma were a gift from Dr. Ovideo Rettori, Universidade Estadual de Campinas, Campinas, SP, Brazil. White male 3- to 5-month-old SpragueDawley rats were used for all the experiments.

\section{Tumors}

Tumor cells were grown in the ascitic and solid forms. Ascitic tumor was obtained by intraperitoneal inoculation of 40 million cells diluted in PBS. After 4 days, cells were removed from the peritoneal cavity by aspiration of ascitic fluid and diluted in PBS, and the number of neoplastic cells was determined.

Solid tumor was obtained by four subcutaneous inoculations of 4 million tumor cells into the dorsal region of male rats. After 7 days, animals bearing tumors were sacrificed and tumors were removed. Metabolic radiolabeling of tumors was performed by intraperitoneal injections of $2 \mathrm{mCi}\left[{ }^{35} \mathrm{~S}\right]-$ sulfate (IPEN, São Paulo, SP, Brazil), 6 h before sacrifice.

\section{Isolation of glycosaminoglycans}

Tumors were ground with 10 volumes of acetone and after standing overnight at $-20^{\circ} \mathrm{C}$ the mixture was centrifuged. One gram of the dried precipitate was then resuspended in $10 \mathrm{ml}$ of $50 \mathrm{mM}$ Tris- $\mathrm{HCl}$ buffer, $\mathrm{pH} 8.0$, containing $0.15 \mathrm{M} \mathrm{NaCl}$ and $2 \mathrm{mg} / \mathrm{ml}$ maxatase (Biocon, Rio de Janeiro, RJ, Brazil). The mixture was incubated overnight at 
$50^{\circ} \mathrm{C}$ and centrifuged. $\mathrm{NaCl}$ and trichloroacetic acid were added to the supernatant up to $1 \mathrm{M}$ and $10 \%$ of the final concentration, respectively, and the precipitate which formed was removed by centrifugation. Glycosaminoglycans in the supernatant were precipitated with 2 volumes of ethanol $\left(-20^{\circ} \mathrm{C}, 24 \mathrm{~h}\right)$. The ethanol precipitate collected by centrifugation was dried and incubated with DNase I in $50 \mathrm{mM}$ sodium acetate, $\mathrm{pH} 6.0$, for $18 \mathrm{~h}$ at $37^{\circ} \mathrm{C}$. Qualitative and quantitative analyses of glycosaminoglycans were performed by agarose gel electrophoresis.

\section{Isolation of proteoglycans}

Proteoglycans were extracted from diced solid tumor tissue in a dissociative solution containing $4 \mathrm{M} \mathrm{GuaHCl}$ in $50 \mathrm{mM}$ sodium acetate, $\mathrm{pH}$ 6.0, proteinase inhibitors (100 $\mathrm{mM} \alpha$-aminocaproic acid, $6.5 \mathrm{mM}$ benzamidine $\mathrm{HCl}, 5.5 \mathrm{mM}$ iodoacetamide, and 0.1 $\mathrm{mM}$ phenylmethylsulfonyl fluoride, $5 \mathrm{ml} / \mathrm{g}$ of tissue). The homogenate was centrifuged and the precipitation step was repeated. Both supernatant solutions were precipitated with 2 volumes of ethanol. The supernatant was removed by centrifugation and excess ethanol was evaporated to dryness. The ethanol precipitates were re-dissolved in $6 \mathrm{M}$ urea buffered with $25 \mathrm{mM}$ Tris- $\mathrm{HCl}, \mathrm{pH} 6.8$, and ultracentrifuged $\left(100,000 \mathrm{~g}, 30 \mathrm{~min}, 4^{\circ} \mathrm{C}\right)$ before being submitted to ion-exchange chromatography on DEAE-cellulose.

\section{Ion-exchange chromatography}

The solution containing proteoglycans in $6 \mathrm{M}$ urea buffered with $25 \mathrm{mM}$ Tris- $\mathrm{HCl}, \mathrm{pH}$ 6.8 , added to DEAE-cellulose $(0.1 \mathrm{ml} / \mathrm{g}$ wet tissue) was submitted to gentle shaking. After $12 \mathrm{~h}$ at $4^{\circ} \mathrm{C}$ the resin was packed into a glass chromatography column and washed with 30 volumes of $6 \mathrm{M}$ urea. Elution was performed in Tris-buffered urea containing $0.2 \mathrm{M} \mathrm{NaCl}$ (30 volumes) and $2 \mathrm{M} \mathrm{NaCl}$
(5 volumes). Proteoglycans (radioactivity) were eluted with the second eluate and then dialyzed against distilled water and lyophilized.

\section{Hydrophobic interaction chromatography}

Materials eluted with $2 \mathrm{M} \mathrm{NaCl}$ from DEAE-cellulose were added to Octyl-Sepharose CL-4B ( $0.5 \mathrm{ml} / \mathrm{g}$ wet tissue), previously equilibrated with $0.15 \mathrm{M}$ sodium acetate, $\mathrm{pH}$ 6.3 , containing $1 \mathrm{M} \mathrm{GuaHCl}$, for $12 \mathrm{~h}$ at $4^{\circ} \mathrm{C}$. Resin was packed in a glass chromatography column and washed with 5 volumes of 0.15 $\mathrm{M}$ sodium acetate, $\mathrm{pH} 6.3$, containing $1 \mathrm{M}$ GuaHCl (fraction Oc-1M) and eluted with 5 volumes of $0.15 \mathrm{M}$ sodium acetate, $\mathrm{pH} 6.3$, containing $6 \mathrm{M} \mathrm{GuaHCl}$ (fraction Oc-6M). Both Oc-1M and Oc-6M were dialyzed exhaustively against distilled water, lyophilized and resuspended in $50 \mathrm{mM}$ sodium acetate, $\mathrm{pH} 5.8$, containing $4 \mathrm{M} \mathrm{GuaHCl}$.

\section{Size-exclusion chromatography}

Fractions obtained by Octyl-Sepharose chromatography, Oc-1M and Oc-6M, were further chromatographed separately on Sepharose CL-4B columns $(112 \times 1.5 \mathrm{~cm})$ equilibrated and eluted with $4 \mathrm{M} \mathrm{GuaHCl}$ and $50 \mathrm{mM}$ sodium acetate, $\mathrm{pH} 5.8$, at a flow rate of $0.5 \mathrm{ml} / \mathrm{min}$. The effluent collected (2 $\mathrm{ml}$ ) was monitored at $280 \mathrm{~nm}$ and an aliquot was used to determine the amount of radioactivity. Fractions containing proteoglycans were pooled, dialyzed against distilled water, and lyophilized.

\section{Agarose gel electrophoresis}

Proteoglycans and glycosaminoglycans were identified and quantified by agarose gel electrophoresis in $50 \mathrm{mM} \mathrm{1,3-diamino-}$ propane buffer, $\mathrm{pH} 9.0$, by the method of Dietrich and Dietrich (15). Electrophoresis was performed for about $1 \mathrm{~h}$ at $100 \mathrm{~V}$ and compounds were precipitated in the gel with 
0.1\% Cetavlon (N-acetyl-N,N,N-trimethylammonium bromide) for at least $2 \mathrm{~h}$. The gel was dried and stained with $0.1 \%$ toluidine blue in $1 \%$ acetic acid and $50 \%$ ethanol. For HA visualization, the gel was stained with $0.1 \%$ toluidine blue in $25 \mathrm{mM}$ sodium acetate buffer, pH 5.0. Glycosaminoglycan identification was based on the migration of the compounds compared to standards. Quantification was carried out by densitometry at $530 \mathrm{~nm}$, with the error of the method being about $5 \%$. Gel slices were cut and counted in scintillation liquid for identification of $\left[{ }^{35} \mathrm{~S}\right]-$ sulfate-radiolabeled proteoglycan and glycosaminoglycan.

Preparative gel electrophoresis was performed as a last proteoglycan purification step. Different proteoglycans were separated according to their differential electrophoretic mobility. Agarose gel was cut and the gel containing proteoglycans was eluted by centrifugation after freezing and thawing the agarose gel.

\section{SDS-PAGE}

Electrophoresis for protein analysis was carried out on $6 \%$ polyacrylamide gels containing SDS. Protein bands were detected by silver staining (16), Coomassie blue R-250 staining, or with specific antibodies by immunoblotting, while glycosaminoglycan and proteoglycan were stained with toluidine blue.

\section{Immunoblotting}

Proteoglycans electrophoresed on agarose gel were transferred to nitrocellulose sheets by diffusion, while materials on polyacrylamide gels were electrotransferred to nitrocellulose sheets. Decorin antiserum (anti-pig cartilage decorin) was used at 1:5,000 dilution. Bound antibodies were localized with a biotin-conjugated second antibody $(1: 10,000)$ and peroxidase-conjugated streptavidin $(1: 10,000)$.

\section{Characterization of proteoglycans}

Samples of the protein cores were prepared by digesting the proteoglycan $(10 \mu \mathrm{g})$ with chondroitinase $\mathrm{ABC}(0.2 \mathrm{mU} / \mu \mathrm{g}$ proteoglycan) in $100 \mathrm{mM}$ Tris- $\mathrm{HCl}, 10 \mathrm{mM}$ sodium fluoride, containing the mixture of protease inhibitors described earlier at $\mathrm{pH}$ 7.3 , for $18 \mathrm{~h}$ at $37^{\circ} \mathrm{C}$.

Relative size and electrophoretic migration of glycosaminoglycan chains attached to the proteoglycan were determined after alkaline B-elimination $(0.5 \mathrm{M} \mathrm{NaOH}, 1 \mathrm{M}$ $\left.\mathrm{NaBH}_{4}, 50^{\circ} \mathrm{C}, 16 \mathrm{~h}\right)$. Solutions were neutralized with acetic acid, dialyzed against distilled water and lyophilized.

The relative contents of disaccharides of the glycosaminoglycan chains were determined by descending paper chromatography after chondroitinase $\mathrm{B}, \mathrm{AC}$ and $\mathrm{ABC}$ treatment. About $20 \mu \mathrm{g}$ of proteoglycan were incubated with $15 \mathrm{mU}$ of enzyme for $18 \mathrm{~h}$ in $10 \mathrm{mM}$ Tris-acetate buffer, $\mathrm{pH} 7.5$, at room temperature (chondroitinase $\mathrm{B}$ ), or in $50 \mathrm{mM}$ Tris-acetate buffer, $\mathrm{pH} 8.0$, at $37^{\circ} \mathrm{C}$ (chondroitinase $\mathrm{AC}$ and $\mathrm{ABC}$ ).

The N-terminal amino acid sequence of the protein core was determined with an automatic protein and peptide sequencer (model ABI 476A, Perkin-Elmer, Foster City, CA, USA).

\section{Analytical procedures}

Protein content was determined by the method of Spector (17) using Coomassie blue G-250, with bovine serum albumin as standard.

\section{Results}

\section{Glycosaminoglycan contents of Walker 256 tumor}

Solid Walker 256 tumor was shown to contain glycosaminoglycans by agarose gel electrophoresis. The major sulfated gly- 
A

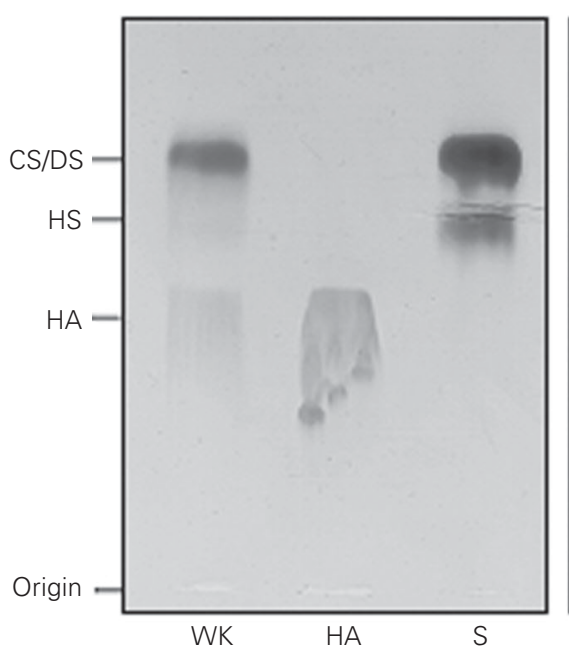

B

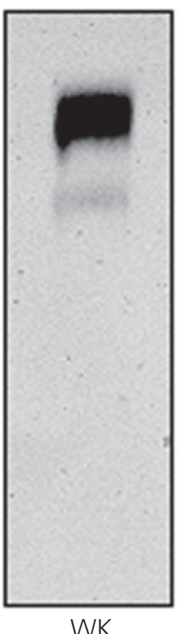

C

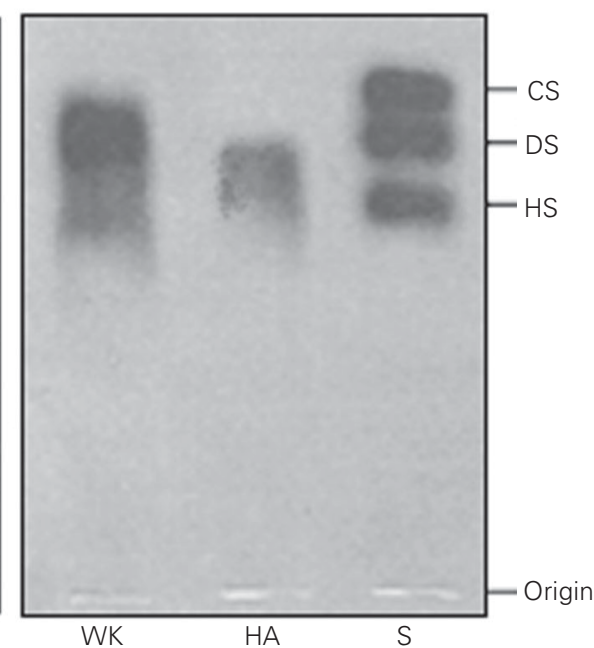

Figure 1. Glycosaminoglycan composition of Walker 256 carcinoma. About $10 \mu \mathrm{g}$ glycosaminoglycan obtained after Walker 256 carcinoma (WK) proteolysis was applied to an agarose gel slab in $50 \mathrm{mM}$ Tris-acetate buffer, pH 8.0 (A), or in $50 \mathrm{mM}$ 1,3-propylenediamine-acetate buffer, pH 9.0 (C), and subjected to electrophoresis at $4^{\circ} \mathrm{C}$. $B$, Autoradiography of the agarose gel electrophoresis presented in panel A. Glycosaminoglycan chains were visualized after fixation with Cetavlon, drying and staining with toluidine blue. Quantification was performed by densitometry and results are reported in Table 1. CS, chondroitin sulfate; DS, dermatan sulfate; HA, hyaluronic acid; HS, heparan sulfate; S, standard sulfated glycosaminoglycan.

cosaminoglycan chains had an intermediate migration between DS and CS shown by toluidine blue staining (Figure 1C) and by $\left[{ }^{35} \mathrm{~S}\right]$-sulfate-incorporated glycosaminoglycan (Figure 1B). It corresponded to about $90 \%$ of total sulfated glycosaminoglycan in the tissue (Table 1). The remaining 10\% sulfated glycosaminoglycan corresponded to HS. Additionally, a large amount of HA was also observed (Figure 1A,C).

\section{Proteoglycan purification}

Proteoglycans were extracted from solid tumors of Walker 256 rat carcinoma and subsequently purified for analysis of the proteoglycans that could be bearing CS/DS chains. Proteoglycans were extracted from tissue with $4 \mathrm{M}$ GuaHCl and submitted to DEAE-cellulose chromatography, and then to Octyl-Sepharose CL-4B chromatography. Analysis of the hydrophobic fractions by agarose gel electrophoresis showed separation of the fraction which interacts with Octyl-
Table 1. Walker 256 carcinoma sulfated glycosaminoglycans.

\begin{tabular}{lcc}
\hline & $\begin{array}{c}\text { Sulfated } \\
\text { glycosaminoglycan } \\
(\mu \mathrm{g} / \mathrm{g} \text { dry tissue) }\end{array}$ & $\begin{array}{c}\text { Specific activity } \\
\left(\mathrm{cpm} \times 10^{3} / \mathrm{g}\right. \\
\text { dry tissue) }\end{array}$ \\
\hline CS/DS & 1069.6 & 2984.4 \\
HS & 132.1 & 326.4 \\
\hline
\end{tabular}

The amount of each sulfated glycosaminoglycan (CS/DS, chondroitin sulfate/dermatan sulfate; HS, heparan sulfate) was determined by densitometry of the electrophoresis gel stained with toluidine blue (Figure 1). The total amount of [ $\left.{ }^{35} \mathrm{~S}\right]$-sulfate incorporated into each sulfated glycosaminoglycan was determined after cutting the gel and counting in scintillation liquid.

Sepharose, corresponding to about $30 \%$ of total sulfated glycosaminoglycan (Oc-6M). The other fraction, which did not interact with Octyl-Sepharose (Oc-1M), was composed of bands with different electrophoretic mobility, possibly representing different proteoglycans. Fraction Oc-6M showed a single proteoglycan band, while fraction 
Oc-1M seemed to consist of a mixture of proteoglycans, since more than one band was observed following electrophoretic separation on agarose gel (Figure 2). Both fractions were rechromatographed separately on Sepharose CL-4B columns (Figure 3). The two fractions have the same $k_{\mathrm{av}}(0.44)$, although fraction Oc-1M has a wider elution profile, indicating that there is more than one component, as shown previously in Figure 2. These proteoglycans might have different molecular weights. A pool of the Oc-6M fraction was submitted to preparative agarose gel electrophoresis for further characterization.

\section{Characterization of proteoglycan Oc-6M}

Fraction proteoglycan Oc-6M was analyzed before and after alkaline $B$-elimination by agarose (Figure 4A) and polyacrylamide gel electrophoresis (Figure 4B). Free glycosaminoglycan chains showed intermediate agarose electrophoretic migration between CS and DS standards, and a molecular weight of about $45 \mathrm{kDa}$. Intact proteoglycan had an 85-kDa molecular weight and electrophoretic migration similar to that of standard HS on agarose gel. Yet, this proteoglycan cross-reacted with an antiserum raised against pig laryngeal cartilage decorin (Figure 4C).

Proteoglycan Oc-6M was incubated with chondroitinase for analysis of glycosaminoglycan structure and was found to be partially degraded by chondroitinase $\mathrm{AC}$ and totally degraded by chondroitinase ABC (Figure 5). Only 4-sulfated disaccharides were present in the structure. After incubation with chondroitinase $\mathrm{B}$, which degrades only the $B(1 \rightarrow 4)$ linkage between acid $\mathrm{N}$-acetylD-galactosamine and L-iduronic acid, only small amounts of 4-sulfated disaccharides were released. The amount of unsaturated 4sulfated disaccharides obtained by the action of chondroitinase $\mathrm{AC}$ was equal to $50 \%$ of the total disaccharides obtained by the action of chondroitinase ABC. Since chondroitinase $A C$ acts on $B(1 \rightarrow 4)$ linkages between hexosamine and D-glucuronic acid, these data indicated the presence of Liduronic acid residues in the molecule, permitting us to classify it as a DS. The differences in electrophoretic migration on agarose gel between CS and DS were due to their differences in L-iduronic acid and Dglucuronic acid proportions.

Fraction proteoglycan Oc-6M was incubated with chondroitinase $\mathrm{ABC}$ to analyze the core protein. There were at least three different sized core proteins with molecular weights of 56,46 and $36 \mathrm{kDa}$ detected by Coomassie blue (Figure 6A) and by immunoblotting using anti-decorin antibodies (Figure $6 \mathrm{~B}$ ).

$\mathrm{N}$-terminal amino acid sequencing of proteoglycan Oc-6M showed a single sequence (Figure 7). Although it was not possible to identify residues at positions 17 and 19 , this was confirmed to be decorin because of its homology with core proteins of mouse decorin and by homology with decorin core protein of other species.

\section{Discussion}

We examined the glycosaminoglycan and proteoglycan composition of Walker 256 rat mammary carcinoma. Besides HA, there were large amounts of sulfated glycosaminoglycan. About $90 \%$ of total sulfated glycosaminoglycan corresponded to CS/DS chains, and the remaining ones to HS. The presence of HA in Walker 256 rat mammary carcinoma has been previously described by FiszerSzafars and Giullino (12). In other tumors, the presence of HA has been correlated with invasive and metastatic behavior since an extracellular matrix rich in HA becomes more hydrated and can support adhesion and locomotion of tumoral cells (18).

Our analysis of Walker 256 rat carcinoma proteoglycans indicated the production of different proteoglycans bearing CS and/or 

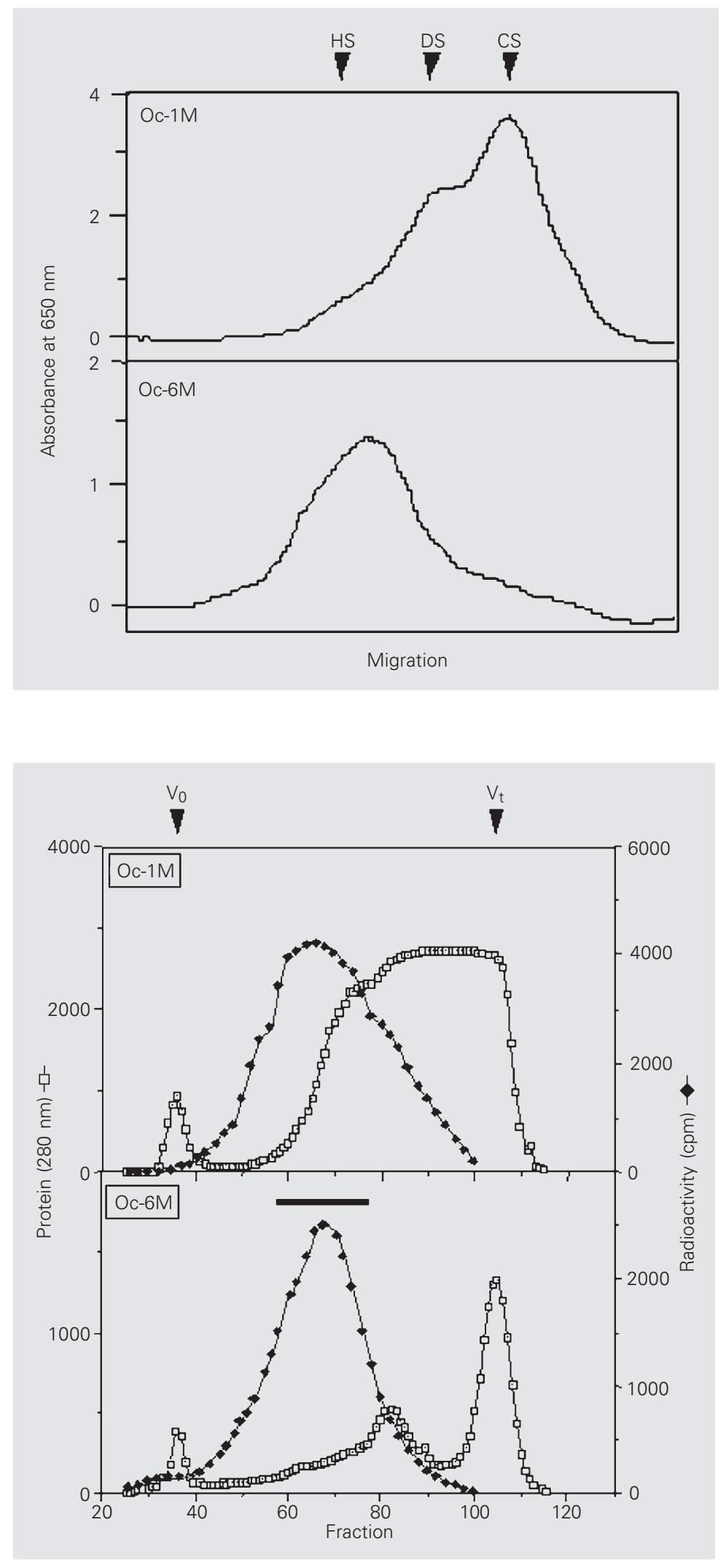

Figure 2. Densitometric profiles of proteoglycans obtained from Walker 256 carcinoma before and after Octyl-Sepharose $\mathrm{CL}-4 \mathrm{~B}$ chromatography and subjected to agarose gel electrophoresis. Proteoglycans eluted with $2 \mathrm{M} \mathrm{NaCl}$ from DEAE-cellulose were chromatographed on Octyl-Sepharose $\mathrm{CL}-4 \mathrm{~B}$. Proteoglycans were divided into two fractions: one that was eluted with $1 \mathrm{M} \mathrm{GuaHCl}(\mathrm{Oc}-1 \mathrm{M})$, and the other eluted with $6 \mathrm{M} \mathrm{GuaHCl}(\mathrm{Oc}-6 \mathrm{M})$. Aliquots of each fraction were subjected to agarose gel electrophoresis $(50 \mathrm{mM}$ 1,3propylenediamine-acetate buffer, pH 9.0). After fixation, drying and staining the gel slab was exposed to an X-ray film. The figure shows the densitometric profiles of autoradiography of both fractions separated after Octyl-Sepharose CL4B chromatography. CS (chondroitin sulfate), DS (dermatan sulfate) and HS (heparan sulfate) are standard sulfated glycosaminoglycans.

Figure 3. Sepharose CL-4B elution profiles of proteoglycans from Walker 256 carcinoma. Fractions Oc-1M and Oc-6M from Octyl-Sepharose CL-4B were chromatographed on Sepharose CL-4B, which was equilibrated and eluted with 4 $\mathrm{M} \mathrm{GuaHCl}, 50 \mathrm{mM}$ sodium acetate, $\mathrm{pH}$ 5.8. Protein $(20 \mu \mathrm{l})$ and sulfated glycosaminoglycans $(30 \mu)$ were determined by absorbance and radioactivity, respectively, in the $2 \mathrm{ml}$ fractions collected. Fractions containing proteoglycans were pooled as indicated by the upper horizontal bar in the lower panel, dialyzed and lyophilized for further purification. $V_{0}=$ void volume; $V_{t}=$ totally included volume. 
Figure 4. Electrophoretic analysis of proteoglycan fraction Oc-6M. A, About $0.5 \mu \mathrm{g}$ Oc-6M proteoglycan (W) and control cartilage pig decorin (Dec) was subjected to agarose gel electrophoresis $(50 \mathrm{mM}$ 1,3-diaminopropane buffer, $\mathrm{pH}$ 9.0) and transferred to a nitrocellulose membrane. Immunostaining was performed using decorin antiserum and the biotin-streptavidin-peroxidase complex. $B$, About $5 \mu \mathrm{g}$ proteoglycan Oc-6M was subjected to agarose gel electrophoresis $(50 \mathrm{mM}$ 1,3-diaminopropane buffer, $\mathrm{pH}$ 9.0) before (-) and after (+) alkaline ß-elimination as described in Methods. CS, chondroitin sulfate; DS, dermatan sulfate; HS, heparan sulfate; S, standard glycosaminoglycans. C, About 15 $\mu \mathrm{g}$ proteoglycan Oc-6M was subjected to a $6 \%$ SDSPAGE before (-) and after (+) alkaline ß-elimination. Gel was fixed with $10 \%$ acetic acid and $25 \%$ methanol and stained with toluidine blue. Molecular weight standards for glycosaminoglycan are: chondroitin 6-sulfate (58 $\mathrm{kDa})$, chondroitin 4-sulfate (21 kDa), heparan sulfate C (9.9 kDa), and heparan sulfate D (4.5 kDa)

Figure 5. Relative amounts of unsaturated 4-sulfated disaccharides ( $\triangle \mathrm{Di}-4 \mathrm{~S}$ ) formed by the action of different chondroitinases on Oc-6M proteoglycan (PG). About 20 $\mu \mathrm{g}$ purified $P G$ was incubated with chondroitinase $B$, $A C$ and $A B C$ in a final volume of $15 \mu \mathrm{l}$. The incubation mixtures were applied to Whatman No. 1 filter paper and chromatographed in isobutiric acid, $1 \mathrm{M} \mathrm{NH}_{4} \mathrm{OH}$ $(5: 3, v / v)$. The unsaturated products formed were visualized by UV light and by alkaline silver staining. The figure shows the relative amounts of degradation calculated by densitometry of unsaturated 4-sulfated disaccharide bands after silver staining.

Figure 6. SDS-PAGE and immunoblotting of proteoglycan (PG) Oc-6M from Walker 256 carcinoma. About 1 $\mu \mathrm{g}$ purified PG was incubated for $18 \mathrm{~h}$ with $0.1 \mathrm{M}$ Trisacetate buffer, $\mathrm{pH} 7.3$, in the presence of protease inhibitors at $37^{\circ} \mathrm{C}$ and in the presence (+) or absence $(-)$ of $2 \mathrm{mU}$ chondroitinase $A B C$ (Chase $A B C$ ). Intact PG and $C$ hase $A B C$ digested core protein were subjected to SDS-PAGE and stained with Coomassie blue (A), and decorin antiserum after transferring to a nitrocellulose membrane (B).
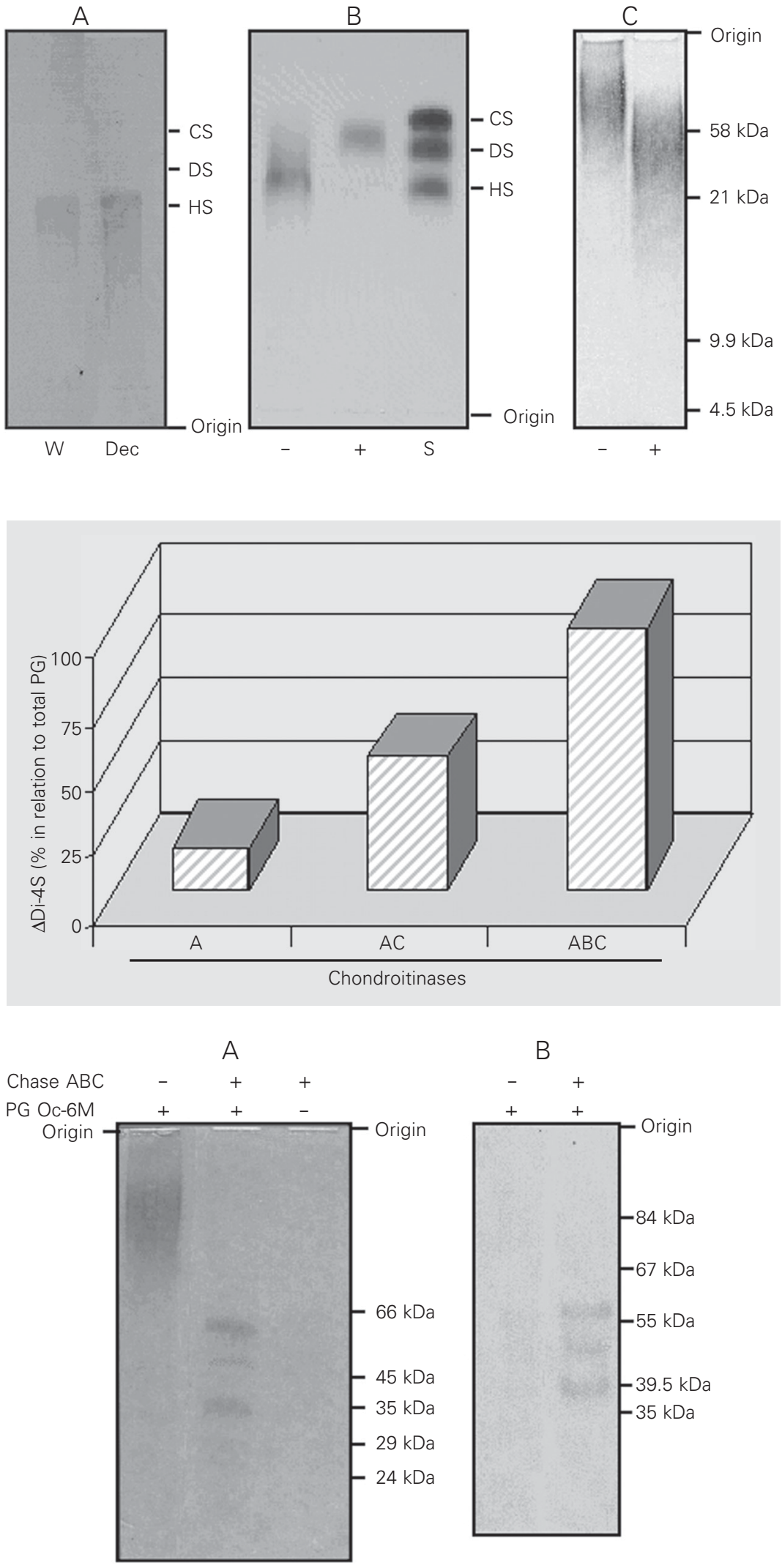


\begin{tabular}{|c|c|c|c|c|c|c|c|c|c|c|c|c|c|c|c|c|c|c|c|c|}
\hline & 1 & & & $*$ & 5 & & & & & 10 & & & & & 15 & & & & & 20 \\
\hline & $\bar{D}$ & $\mathrm{E}$ & A & S & $\bar{G}$ & I & I & & $\mathrm{Y}$ & $\overline{\mathrm{D}}$ & $\mathrm{P}$ & D & $\mathrm{N}$ & $\mathrm{P}$ & $\mathrm{L}$ & & & & & $\mathrm{P}$ \\
\hline & D & $\mathrm{E}$ & A & $\mathrm{S}$ & $\mathrm{G}$ & I & I & & $Y$ & $\mathrm{D}$ & $\mathrm{P}$ & $\mathrm{D}$ & & & & & & $\mathrm{M}$ & & $P$ \\
\hline & D & $\mathrm{E}$ & A & S & $\mathrm{G}$ & I & I & $\mathrm{P}$ & Y & D & $\mathrm{P}$ & $\mathrm{D}$ & $\mathrm{N}$ & & $\mathrm{L}$ & $\mathrm{I}$ & & $\mathrm{M}$ & $\mathrm{C}$ & $\mathrm{P}$ \\
\hline & D & $\mathrm{E}$ & A & S & $\mathrm{G}$ & I & $\mathrm{G}$ & $\mathrm{P}$ & $\mathrm{E}$ & $\mathrm{V}$ & $\mathrm{P}$ & D & $\mathrm{D}$ & & $\mathrm{D}$ & & & $\mathrm{P}$ & $\mathrm{S}$ & $\mathrm{L}$ \\
\hline & D & $\mathrm{E}$ & A & $\mathrm{S}$ & $\mathrm{G}$ & I & $\mathrm{G}$ & $\mathrm{P}$ & $\mathrm{E}$ & $\mathrm{E}$ & $\mathrm{H}$ & $\Gamma$ & $\mathrm{P}$ & $\mathrm{E}$ & $\mathrm{V}$ & $r$ & $\mathrm{E}$ & 1 & $\mathrm{E}$ & $\mathrm{P}$ \\
\hline & D & $\mathrm{E}$ & A & $\mathrm{S}$ & $\mathrm{G}$ & I & $\mathrm{G}$ & $\mathrm{P}$ & $\mathrm{D}$ & $\mathrm{E}$ & $\mathrm{L}$ & A & $\mathrm{P}$ & $\mathrm{E}$ & $\mathrm{L}$ & $\mathrm{L}$ & $\mathrm{E}$ & D & D & $\mathrm{L}$ \\
\hline & D & $\mathrm{E}$ & $\mathrm{G}$ & $\mathrm{S}$ & $\mathrm{A}$ & & $\mathrm{M}$ & & $\mathrm{P}$ & $\mathrm{T}$ & $\mathrm{D}$ & $\mathrm{D}$ & $\mathrm{P}$ & V & & $\mathrm{S}$ & $\mathrm{G}$ & $\mathrm{F}$ & & \\
\hline
\end{tabular}

Figure 7. Amino acid sequences of decorin core proteins of Walker 256 tumor and comparison with other species. N-terminal sequences: a, Walker 256 carcinoma; b, rat (19); c, mouse (20); d, human (21); e, bovine (22); f, rabbit (23); g, chicken (24). The identical residues are enclosed in boxes. ${ }^{*}$ Indicates the putative glycosaminoglycan attachment site.

DS chains. We identified and characterized the small leucine-rich proteoglycan, decorin, as one of the proteoglycans present in Walker 256 carcinoma. Decorin was characterized as a DS proteoglycan with three core proteins $(36,46$ and $56 \mathrm{kDa})$. The different mRNA and/or core protein sizes generated by alternative splicing have been described for several proteoglycans, suggesting that this phenomenon amounts to a functional difference for the resulting proteoglycans: aggrecan $(25,26)$, versican/PG-M (27-29), agrin (30), perlecan (31), and phosphacan (32). As far as we know, there is no such report related to decorin. When the decorin gene was analyzed, two leader exons were observed, which could be alternatively spliced. However, this did not affect the ultimate protein sequence since they were in an untranslated region (33). Thus, different core proteins found in decorin from Walker 256 carcinoma might be generated by in vivo proteolysis or during the isolation and purification process. It is well known that tumors produce many proteinases responsible for the degradation of matrix components, thereby facilitating tumor invasion (34).

Decorin has been described as an antitumoral molecule because of its ability to modulate cell growth and of its effects on several key elements including matrix assembly, growth factor binding, and receptor tyrosine kinase activity (6). Decorin may interact with TGF- $\beta$ and with p21, both of which are relevant to carcinogenesis and tumor progression (35). Decorin binds to TGF- $\beta$ and blocks TGF- $\beta$-dependent growth stimulation or cell inhibition, suggesting that its mechanism of action is the neutralization of TGF- $\beta$ activity (36). Decorin may directly induce growth suppression by up-regulating p21, a potent inhibitor of cyclin-dependent kinases (37). Decorin binds to the epidermal growth factor receptor, leading to activation of the mitogen-activated protein kinase signal (38), with consequent mobilization of intracellular calcium (39), and an increase in endogenous p21 (32) resulting in ultimate growth suppression $(7,8)$. Decorin mRNA and protein levels are markedly increased in the peritumoral stroma of human colon cancers $(10,40)$. This may represent a natural biological response by the host connective tissue cells to the invading neoplastic cells. Decorin is one of the proteoglycans found in Walker 256 rat mammary carcinoma, but there are other proteoglycans containing sulfated glycosaminoglycan (CS and HS), which corresponds to about $50 \%$ of total sulfated glycosaminoglycan.

Further studies are necessary to characterize the other proteoglycans, which may also play an important role in tumor growth and progression, as demonstrated for decorin. 


\section{References}

1. Sampaio LO, Dietrich CP \& Gianotti Filho O (1977). Changes in the sulfated mucopolysaccharide composition in mammalian tissue during growth and in cancer tissue. Biochimica et Biophysica Acta, 498: 123-131.

2. Hassel JR, Robey PG, Barrach HJ, Wilczek J, Rennard SI \& Martin GR (1980). Isolation of a heparan sulfate-containing proteoglycan from basement membrane. Proceedings of the National Academy of Sciences, USA, 77: 4494-4498.

3. Paulus W, Bau I, Dours-Zimmermann MT \& Zimmermann DR (1996). Differential expression of versican isoforms in brain tumors. Journal of Neuropathology and Experimental Neurology, 55: 528-533.

4. Isogai Z, Shinomura T, Yamakawa N, Takeuchi J, Tsuji T, Heinegård D \& Kimata K (1996). 2B1 antigen characteristically expressed on extracellular matrices of human malignant tumors is a large chondroitin sulfate proteoglycan, PG-M/versican. Cancer Research, 56: 3902-3908.

5. Hunzelmann N, Schunherr E, Bonnekoh B, Hartmann C, Kresse H \& Kieg $T$ (1995). Altered immunohistochemical expression of small proteoglycans in the tumor tissue and stroma of basal cell carcinoma. Journal of Investigative Dermatology, 104: 509-513.

6. Iozzo RV (1999). The biology of small leucine-rich proteoglycans. Journal of Biological Chemistry, 274: 18843-18846.

7. Santra M, Skorski T, Calabretta B, Lattime EC \& lozzo RV (1995). De novo decorin gene expression suppresses the malignant phenotype in human colon cancer cells. Proceedings of the National Academy of Sciences, USA, 92: 7016-7020.

8. Santra M, Mann DM, Mercer EW, Skorski T, Calabretta B \& lozzo RV (1997). Ectopic expression of decorin protein core causes a generalized growth suppression in neoplastic cells of various histogenic origin and requires endogenous p21, an inhibitor of cyclin-dependent kinases. Journal of Clinical Investigation, 100: 149-157.

9. Iozzo RV \& Cohen I (1993). Altered proteoglycan gene expression and the tumor stroma. Experientia, 49: 447-455.

10. Adany R, Heimer R, Caterson B, Sorrell JM \& lozzo RV (1990). Altered expression of chondroitin sulfate proteoglycan in the stroma of human colon carcinoma. Hypomethylation of PG-40 gene correlates with increased content and mRNA levels. Journal of Biological Chemistry, 265: 11389-11396.

11. Earle WR (1935). A study of the Walker rat mammary carcinoma 256, in vivo and in vitro. American Journal of Cancer, 24: 566-612.

12. Fiszer-Szafarz B \& Giullino PM (1970). Hyaluronic acid content of the interstitial fluid of Walker carcinoma 256. Proceedings of the Society for Experimental Biology and Medicine, 133: 805-807.

13. Dietrich CP \& Nader HB (1974). Fractionation and properties of four heparitin sulfates from beef lung tissues. Isolation and characterization of a homogeneous species of heparitin sulfate. Biochimica et Biophysica Acta, 343: 34-44.

14. Sampaio LO, Bayliss MT, Hardingham TE \& Muir H (1988). Dermatan sulphate proteoglycan from human articular cartilage. Variation in its contents with age and structural comparison with a small chondroitin sulphate proteoglycan from pig laryngeal cartilage. Biochemical Journal, 254: 757-764.

15. Dietrich CP \& Dietrich SMC (1976). Electrophoretic behaviour of acidic mucopolysaccharides in diamine buffers. Analytical Biochemistry, 70: 645-647.

16. Ansorge W (1985). Fast and sensitive detection of protein and DNA bands by treatment with potassium permanganate. Journal of Biochemical and Biophysical Methods, 11: 13-20.

17. Spector $T$ (1978). Refinement of the Coomassie blue method of protein quantification. A simple and linear spectrophotometric assay for less than 0.5 to $50 \mathrm{\mu g}$ of protein. Analytical Biochemistry, 86: 142-146.

18. Turley EA (1992). Hyaluronan and cell locomotion. Cancer and Metastasis Reviews, 11: 21-30.

19. Abramson SP \& Woessner Jr JF (1992). cDNA sequencing of rat dermatan sulfate proteoglycan-II (decorin). Biochimica et Biophysica Acta, 1132: 225-227.

20. Asundi VK \& Dreher KL (1992). Molecular characterisation of vascular smooth muscle decorin: deduced core protein structure and regulation of gene expression. European Journal of Cell Biology, 59: 314-321.

21. Krusius T \& Ruoslahti E (1986). Primary structure of an extracellular matrix proteoglycan core protein deduced from cloned cDNA. Proceedings of the National Academy of Sciences, USA, 83: 7683-7687.

22. Day AA, McQuillan Cl, Termine JD \& Young MR (1987). Molecular cloning and sequence analysis of the cDNA for small proteoglycan II of bovine bone. Biochemical Journal, 248: 801-805.

23. Parthasarathy N, Chandrasekaran L \& Tanzen ML (1991). The major proteoglycan of adult rabbit skeletal muscle. Relationship to small proteoglycans of other tissues. Biochemical Journal, 274: 219-223.

24. Li W, Vergnes JP, Cornuet PK \& Hassell JR (1992). cDNA clone to chick corneal chondroitin/dermatan sulfate proteoglycan reveals identity to decorin. Archives of Biochemistry and Biophysics, 296: 190-197.

25. Baldwin CT, Reginato AM \& Prockop DJ (1989). A new epidermal growth factor like domain in the human core protein of the large cartilage-specific proteoglycan. Evidence for an alternative splicing of the domain. Journal of Biological Chemistry, 264: 15747-15750.

26. Doege K, Sasaki M, Kimura T \& Yamada Y (1991). Complete coding sequence and deduced primary structure of the human cartilage large aggregating proteoglycan aggrecan. Human specific repeats, and additional alternatively spliced forms. Journal of Biological Chemistry, 266: 894-902.

27. Dours-Zimmermann MT \& Zimmermann DR (1994). A novel glycosaminoglycan attachment domain identification in two alternative splice variants of human versican. Journal of Biological Chemistry, 269: 32992-32998.

28. Ito K, Shinomura T, Zako M, Ujita M \& Kimata K (1995). Multiple forms of mouse PG-M, a large chondroitin sulfate generated by alternative splicing. Journal of Biological Chemistry, 270: 958-965.

29. Zako M, Shinomura T, Ujita M, Ito K \& Kimata K (1995). Expression of PG-M (V3), an alternatively spliced form of PG-M without a chondroitin sulfate attachment region in mouse and human tissues. Journal of Biological Chemistry, 270: 3914-3918.

30. Gesemann M, Cavalli V, Denzer AJ, Brancaccio A, Schumacher B \& Ruegg MA (1996). Alternative splicing of agrin alters its binding to heparin, distroglycan, and the putative agrin receptor. Neuron, 16: 755-767.

31. Noonan DM \& Hassell JR (1993). Perlecan, the large low-density proteoglycan of basement membranes: structure and variant forms. Kidney International, 43: 53-60.

32. Joseph SJ, Ford MD, Barth C, Portbury S, Bartlett PF, Nurcombe V \& Grepherath $U$ (1996). A proteoglycan that activates fibroblast growth factors during early neuronal development is a perlecan variant. Development, 122: 3443-3452.

33. Danielson KG, Frazzio A, Cohen I, Cannizzaro LA, Eichstetter I \& Iozzo RV (1995). The human decorin gene: intron-exon organisation, discovery of two alternatively spliced exons in the $5^{\prime}$ untranslated 
region, and mapping of the gene to chromosome 12q23. Genomics, 15: 146-160.

34. Pauli BU \& Knudson W (1988). Tumor invasion: a consequence of destructive and compositional matrix alterations. Human Pathology, 19: $628-639$

35. Ständer M, Naumann U, Wick W \& Weller M (1999). Transforming growth factor- $\beta$ and $\mathrm{p}-21$ : multiple molecular targets of decorinmediated suppression of neoplastic growth. Cell and Tissue Research, 296: 221-227.

36. Yamaguchi $Y$, Mann DM \& Ruoslahti E (1990). Negative regulation of transforming growth factor- $ß$ by the proteoglycan decorin. Nature, 346: 281-284.

37. De Lucca A, Santra M, Baldi A, Giordano A \& lozzo RV (1996). Decorin-induced growth suppression is associated with upregula- tion of p21, an inhibitor of cyclin-dependent kinases. Journal of Biological Chemistry, 271: 18961-18965.

38. Moscatello DK, Santra M, Mann DM, McQuillan DJ, Wong AJ \& lozzo RV (1998). Decorin suppresses tumor cell growth by activating the epidermal growth factor receptor. Journal of Clinical Investigation, 101: 406-412.

39. Patel S, Santra M, McQuillan DJ, Iozzo RV \& Thomas AP (1998). Decorin activates the epidermal growth factor receptor and elevates cytosolic $\mathrm{Ca}^{2+}$ in A431 carcinoma cells. Journal of Biological Chemistry, 273: 3121-3124.

40. Adany R \& lozzo RV (1991). Hypomethylation of the decorin proteoglycan gene in human colon cancer. Biochemical Journal, 276: $301-$ 306. 